\title{
Systematic Review: UK Studies
}

Out of 43 papers, there were $8 \mathrm{UK}$ studies, perhaps indicating current limitations in the development of survivorship care in the UK. These papers highlight patient needs within survivorship care including side effects of therapy and acute and chronic co-morbidity.

\section{Further Reading}

1. Elliott S, Latini DM, Walker LM, Wassersug R, Robinson JW, ADT Survivorship Working Group. Androgen deprivation therapy for prostate cancer: recommendation to improve patient and partner quality of life. J Sex Med. 2010;7(9):2996-3010.

2. Faithful S, Cockle-Hearne J, Khoo V. Self management after prostate cancer treatment: evaluating the feasibility of providing a cognitive and behavioural programme for lower urinary tract symptoms. BJU Int. 2011;107(5):783-90.

3. Goonewardene AS, Symons M, Sullivan A, McCormack G, Milner V, Makar A. The Worcestershire prostate cancer Survivorship Programme: a new concept for holistic long term care and followup. J Am Coll Surg. 2012a;(1):S143.

4. Goonewardene AS, Symons M, Sullivan A, McCormack G, Milner V, Makar A. The prostate cancer Survivorship Programme: a new concept for holistic long term care and followup. J Clin Oncol. 2012b;(Suppl 1).

5. Goonewardene AS, Symons M, Sullivan A, McCormack G, Milner V, Makar A. The Worcestershire prostate cancer Survivorship Programme: a new concept for holistic long term care and followup. Br J Gen Pract. 2013;63(616):574-5.

6. Harrison AS, Watson EK, Ward AM, Khan NF, Turner D, Adams E, Forman D, Roche MF, Rose PW. Primary health and supportive care needs of long term cancer survivors: a questionnaire survey. J Clin Oncol. 2011;29(15):2091-8.

7. Khan NF, Evans J, Rose PW. Primary care consultation behaviours of long-term, adult survivors. Ann Fam Med. 2010;8(5):418-24.

8. Khan NF, Evans J, Rose PW. Quality of care for chronic diseases in a British cohort of long term cancer survivors in the UK. Br J Gen Pract. 2011;61(584):197-9. 